Article

\title{
Reconciling Groundwater Storage Depletion Due to Pumping with Sustainability
}

\section{Jac van der Gun ${ }^{1, *}$ and Annukka Lipponen ${ }^{2}$}

1 Independent hydrogeologist, Ganzeboomsweg 3C, 7433 ES Schalkhaar, The Netherlands

2 United Nations Economic Commission for Europe, Palais des Nations, CH-1211 Geneva 10, Switzerland; E-Mail: annukka.lipponen@unece.org

* Author to whom correspondence should be addressed; E-Mail: j.vandergun@ home.nl; Tel.: +31-570-854-611.

Received: 21 September 2010; in revised form: 17 October 2010 / Accepted: 21 October 2010 / Published: 1 November 2010

\begin{abstract}
Groundwater pumping causes depletion of groundwater storage. The rate of depletion incurred by any new well is gradually decreasing and eventually becomes zero in the long run, after induced recharge and reduction of natural discharge of groundwater combined (capture) have become large enough to balance the pumping rate completely. If aquifer-wide aggregated pumping rates are comparatively large, then such a new dynamic equilibrium may not be reached and groundwater storage may become exhausted. Decisions to pump groundwater are motivated by people's need for domestic water and by expected benefits of using water for a variety of activities. But how much finally is abstracted from an aquifer (or is considered to be an optimal aggregate abstraction rate) depends on a wide range of other factors as well. Among these, the constraint imposed by the groundwater balance (preventing aquifer exhaustion) has received ample attention in the professional literature. However, other constraints or considerations related to changes in groundwater level due to pumping are observed as well and in many cases they even may dominate the decisions on pumping. This paper reviews such constraints or considerations, examines how they are or may be incorporated in the decision-making process, and evaluates to what extent the resulting pumping rates and patterns create conditions that comply with principles of sustainability.
\end{abstract}

Keywords: groundwater development; groundwater storage depletion; socio-economic impacts; environmental impacts; groundwater resources management; sustainability 


\section{Introduction}

Abstracting groundwater changes the local groundwater budget. As Theis [1] describes very clearly, groundwater pumped from a well initially comes from storage in the vicinity of the well, but after sufficient time has elapsed the cone of depression eventually reaches a dynamic equilibrium, with further well discharge being balanced by an increase of the recharge and/or a reduction of the natural discharge. However, before such a new equilibrium is reached, part of the volume of stored groundwater is depleted [2]. The impacts of this storage depletion-made evident by declining groundwater levels - need to be taken into account when groundwater development is planned.

To this end, the local functions of groundwater need to be accurately known. Usually, the current or potential function of groundwater as a source of water to be abstracted for domestic, agricultural or industrial use is well-known. In situ functions of groundwater-i.e., functions groundwater fulfils without being abstracted - are more likely to be overlooked. Such functions include feeding the flow of springs, baseflow of streams and the evapotranspiration of wetlands and shallow-water-table agricultural lands, as well as maintaining the stability of the land surface and preventing the migration of saline water or other poor-quality water into fresh aquifer domains. Even relatively minor declines in groundwater level may substantially affect the performance of these in situ functions.

Decisions on groundwater abstraction are driven by objectives and influenced by constraints, as well as by the time perspective. The objectives of groundwater abstraction usually are directly related to the intended use of the pumped water or - such as in the case of drainage - to what specific environmental conditions are aimed for. Constraints of a technological or financial nature announce themselves immediately and therefore become almost automatically incorporated in any new action. This is different for constraints that play a role only on the longer term or that are related to interests in the physical environment other than groundwater abstraction (e.g., conservation of springs or wetlands). These often tend to be ignored by well users, either due to a lack of awareness of the interlinkages and the long response times, or because their personal interests are conflicting with those of third parties or the entire community. In such cases, intervention by a mandated water resources management institution may be needed to properly balance private interests with societal interests. The latter may be evaluated on the basis of criteria like adequacy of public water supplies, degree of equity in the allocation of water, as well as economic efficiency and sustainability of groundwater development.

This paper looks particularly into the sustainability aspects of aquifer-wide groundwater development. It intends to review constraints and other limiting factors to such development; to examine how these affect or may affect decisions on pumping; and to explore to what extent the resulting pumping rates and patterns may comply with the principles of sustainability. There are many definitions and interpretations of sustainability, ranging from narrow or specific to very general ones. In the most basic and narrow sense, 'sustainable' merely indicates 'capable of being sustained', physically spoken. In the context of groundwater development this might be interpreted as a pumping rate that in principle may be continued forever without exhausting the aquifer, irrespective of whether such a pumping activity is considered desirable or not. At a higher-level perspective, sustainable groundwater development is not only defined by the physical capacity of an aquifer to yield water permanently, but also by a range of subjective conditions to be fulfilled or considerations to be taken into account. As Hiscock et al. [3] put it: "Sustainable groundwater development at global and local 
scales is not the balancing of available aquifer storage to satisfy a single aim such as meeting water users' demands, but the maintenance and protection of the groundwater resource to balance economic, environmental and human (social) requirements." The latter belongs to the realm of groundwater resources management. At the highest level, it is 'overall sustainability' that matters, not the sustainability of single components that contribute to it—such as an individual aquifer. Usually at this level the term 'sustainable development' is used, defined by the World Commission on Environment and Development [4] as follows: "development that meets the needs of the present without compromising the ability of future generations to meet their own needs". It is clear that this term is associated with a higher-order perspective, where several policy fields are integrated.

\section{Sustainable Groundwater Development in a Narrow Sense: Groundwater-Budget Constrained Approaches}

\subsection{Sustainable Pumping, Safe Yield and Sustainable Yield}

In a narrow sense, an aggregate aquifer-wide groundwater abstraction rate may be called sustainable if it can be continued indefinitely without exhausting the aquifer. Hence, "sustainable pumping", as Devlin and Sophocleous [5] call it, requires only that the aquifer's water budget components are capable to adjust themselves to the extent that progressive depletion of groundwater storage is stopped after a certain moment in time. Averaged over time, groundwater recharge then is balancing groundwater discharge again. The higher the aggregate abstraction rate, the more difficult it is for the aquifer to adjust and, beyond a certain rate, this will no longer be possible. In other words: sustainable pumping is water-budget constrained.

Related to this hydrologically defined 'sustainable pumping' are the concepts 'safe yield' and 'sustainable yield'. Both Alley and Leake [6] and Kalf and Woolley [7] provide interesting overviews of these concepts as interpreted over time by different groundwater professionals. The first concept was introduced about one hundred years ago, the second half a century later. The definitions of "safe yield' vary between authors, but what most of them have in common is that apart from the water budget constraint they include another restriction, such as "without dangerous depletion of the storage reserve" [8] or "without producing an undesirable result" [9]. Such an additional restriction introduces a large degree of subjectivity, which over time has repeatedly frustrated groundwater professionals and made several of them call for abandoning the term [6,7]. However, the interpretation of safe yield in practice often seems to be more or less identical to 'sustainable pumping' $[9,10]$. It is difficult to specify to what extent the later introduced concept 'sustainable yield' differs from 'safe yield', because definitions or interpretations are very similar and equally ambiguous.

\subsection{The Groundwater Budget Myth}

Defining the maximum rate of sustainable pumping from an aquifer is one of the key objectives of many groundwater resources assessment studies around the world. This rate corresponds to the maximum intensity of groundwater exploitation that will not lead to exhaustion of groundwater storage, because sooner or later a new dynamic equilibrium will be reached between groundwater inflows and outflows. Lack of critical analysis of the dynamics of groundwater systems had led to the widespread 
and persisting erroneous belief among groundwater specialists all over the world that the maximum sustainable pumping rate from an aquifer would be equal to the long-term rate of natural aquifer recharge. This misconception - baptized "the water budget myth" by Bredehoeft et al. [11] — has been addressed repeatedly in the groundwater literature of the last few decades, for example by Bredehoeft [12,13], Alley et al. [14], Sophocleous [10,15-17], Sophocleus and Devlin [18], Alley and Leake [6], Devlin and Sophocleous [5] and Zhou [19].

What is it all about? Under the "water budget myth" people believe that pumping from an aquifer will lead in the longer run to a new dynamic equilibrium between groundwater inflow and outflow, as long as pumping rates do not exceed the mean rate of recharge. In line with the aforementioned correct description by Theis [1], however, Bredehoeft et al. [11] demonstrate and emphasize that the formal condition for reaching steady state (i.e., no further depletion of groundwater storage) is different. They show that the decrease of groundwater storage continues until pumping is completely balanced by the sum of the decrease in groundwater discharge plus the increase in recharge as induced by pumping. The sum of these adjustments is called 'capture' [20]. Consequently, the maximum sustainable pumping rate from an aquifer is not defined by the aquifer's mean natural recharge, but by the maximum capture that can be produced. The latter depends not only on the mean recharge rate, but also on the specific properties (geometry, hydraulic parameters) and the setting of the aquifer (topography, linkages to surface water systems, etc.), as well as on the pumping configuration. The same variables also determine the time needed to transit from the initial stage, during which pumping is balanced by storage depletion, to the final stage of equilibrium. This transit time is often underestimated, even by hydrogeologists.

Bredehoeft [13] concludes that "the idea that knowing the recharge (by which one generally means the virgin rate of recharge) is important in determining the size of sustainable ground water development is a myth. This idea has no basis in fact." Does this mean that it is useless to assess the recharge of an aquifer, in support of rational planning of groundwater development and management? In our opinion this is clearly not the case. Bredehoeft's conclusion seems an exaggerated statement, perhaps prompted by his strong opposition to the contested "water budget myth" practices and inspired by his atypical example of a circular island aquifer. After all, how can we determine the magnitude of an aquifer's maximum capture? A direct way to measure it is not available: it requires analysis of the dynamic behavior of the aquifer concerned. The groundwater models normally used for such an analysis need to be based on a complete set of data on the aquifer, including its recharge. This is implicitly or explicitly confirmed by any of the papers that discuss the use of simulation models as a basis for assessing capture, e.g., Alley and Leake [6], Kalf and Woolly [7], Zhou [19] and even Bredehoeft [13].

The question remains as to how to proceed, in cases where information, time and/or means are lacking, to develop a full-fledged numerical simulation model to assess maximum capture of an aquifer. It may be argued that in such cases a proxy derived from a mean recharge estimate will often be meaningful, provided that it is based on a professional judgment and knowledge of local conditions. This is supported by the observation that mean natural recharge and maximum capture tend to be positively correlated, often even very closely. Such a correlation is strong in cases where capture is balanced mainly by a reduction of natural groundwater outflow and relatively weak if pumping is accompanied by significant induced or artificial recharge. An experienced hydrogeologist does not 
need a simulation model to conclude that for a closed, arid intermountain groundwater basin like the one described by Bredehoeft [13], the maximum capture is virtually equal to the mean recharge. Why one would need a model is to assess how much time would be required to reach a new dynamic equilibrium after pumping has started. Such a hydrogeologist will recognize as well that for a groundwater system in hydraulic contact with a major permanent surface water body (forming a so-called Dirichlet boundary condition) the maximum capture may not be governed by the mean virgin aquifer recharge, but rather by the potentially induced recharge from that surface water body. Examples of such potentially recharging boundaries are a comparatively large allochtonous river or a large surrounding lake - like the one used by Bredehoeft [13] in his key example. In many other cases it would be possible for a professional hydrogeologist to produce a rough estimate of an aquifer's maximum capture on the basis of mean aquifer recharge and on the assumed capability of groundwater in- and outflow components to adjust to pumping. In practice, this often results in expressing the maximum rate of sustainable pumping as a fraction of the mean virgin groundwater recharge.

\subsection{Groundwater-Budget Constrained Approaches in Practice}

Approaches to manage and control groundwater quantity tend to be dominated by the criterion of hydrological sustainability (i.e., preventing exhaustion of groundwater storage) in areas where the aquifer's function as a source of water supply by pumping is prominent and puts all other aquifer functions in the shade. This is first of all the case in arid and semi-arid regions, where water is scarce and people often cannot afford to give up or reduce pumping in favor of current or potential environmental functions of the groundwater system. In addition, the environmental implications of intensive groundwater abstraction may not be sufficiently understood or local authorities may be hesitant to enforce curtailing groundwater abstraction in areas where economic activity options are perceived as limited. As the economics are a central consideration in decision-making about water resources management and as in situ functions of groundwater are difficult to valuate in monetary terms, the environmental functions may not get sufficient attention when alternatives are compared in terms of costs and benefits. Apart from the application of groundwater-budget constrained approaches to individual aquifers, there are also examples of this approach being applied on a national scale, intended to underpin groundwater management interventions. Two examples will be presented below.

In India, national and state authorities attempt to regulate groundwater abstraction actively. Their objective is to encourage further groundwater development in zones where potential still exists for expansion and to avoid or restrict overexploitation in more stressed zones. To this end they use two main instruments: credits (for establishing new wells) and subsidized energy (electricity supply for groundwater pumping), both controlled by government institutions. The principle is simple: facilities are granted in 'underexploited' zones' (white blocks) and refused or curtailed in overexploited or overexploitation prone zones (black or gray blocks). Criterion for classification according to the degree of exploitation is the abstraction rate divided by the mean rate of recharge, averaged over a relatively large administrative zone (locally called block, mandal or taluk). The mean recharge, used as a proxy for maximum capture, is calculated according to a standardized procedure developed by the Government of India [21,22], on the basis of data produced by the national and state monitoring networks. Application of the methodology reveals that intensive groundwater 
exploitation - encouraged by subsidized energy — has produced conditions that are classified as critical or as overexploitation in many administrative zones, especially in the north western states Haryana, Punjab, Rajasthan and Gujarat, and in the southern states Andhra Pradesh, Karnataka and Tamil Nadu [22,23].

Groundwater quantity management in Oman relies on well permit legislation that has been refined and strengthened several times. Permits are required for new wells, for deepening existing wells, for change of their use and for installing a pump [24]. Permits are granted or refused depending on the state of exploitation of the aquifer zone. This state is judged on the basis of regional groundwater studies, in combination with monitoring data. The basic criterion used is that aquifer exhaustion should be prevented. Only in zones where domestic and irrigation water supplies depend on qanats-locally called 'aflaj' (singular 'falaj') — a more restrictive criterion is used, because the flow rates in qanats are highly sensitive to variations in groundwater level. Groundwater quantity management in Oman is not only restrictive. Many of the studies mentioned above are explicitly intended to identify and analyze options for large artificial recharge schemes, of which a considerable number has been constructed already [25].

\section{Other Constraints and Considerations in Relation to Groundwater Storage Depletion}

\subsection{Responses of Groundwater-Connected Natural Systems to Depletion}

Groundwater storage depletion not only causes a reduction of the volume of groundwater available for being abstracted and an associated increase in the costs of abstraction. It also has repercussions for groundwater-connected natural systems and environmental conditions. Such repercussions include the reduction or disappearance of base flows in streams and spring flows, degeneration of wetlands and zones of water-table agriculture, land subsidence and groundwater quality deterioration by intrusion or upconing of brackish or saline water, or by an induced influx of pollutants.

The importance of the base flow component of stream flow (fed by groundwater) is illustrated by an analysis of 54 streams over a 30 year period by the U.S. Geological Survey indicating an average of 52 percent of the stream flow to be contributed by groundwater. Groundwater contributions ranged from 14 percent to 90 percent in these streams, representing physiographically and climatically different regions [26]. When the groundwater contribution is such, it is evident that reduced groundwater discharge due to depletion can have a serious impact on surface water flows. The influence of a flow reduction is particularly dramatic during low flow periods, when the groundwater component is dominant. The base flow is an important part of the minimum flow that is needed to maintain the water-dependent ecosystems. A reduction of flow also hurts the economic activities of the population (navigation, fishing, etc.). A similar form of groundwater discharge reduction is the reduction or even disappearance of spring flows. This is often the first and virtually irreversible impact of incipient intensive groundwater exploitation in arid and semi-arid zones. Over the last 50 years, springs have stopped flowing in numerous areas around the world and in many cases they are unlikely to reappear [27,28].

Intensive exploitation of groundwater resources may cause a loss or degeneration of important riparian and groundwater dependent ecosystems such as wetlands that are sustained by groundwater discharge. This may lead to a loss of valuable services provided by those ecosystems, including fish, 
fuel wood and spring waters which may be important to the local population's livelihood [29]. Decline of the water table as a result of groundwater storage depletion affects water-table agriculture when the capillary fringe sinks beyond the reach of roots of the crops and soil moisture gets affected.

In coastal zones, the importance of fresh groundwater originating on land and discharging to ecosystems in the sea ("submarine groundwater discharge") is increasingly recognized. The freshwater component interacts with the saline seawater, which may affect coastal water quality and nutrient supplies to near-shore habitats [30]. When groundwater discharge decreases, it causes commonly an increase in sea water temperature and in salinity, which affects the ecosystems. Groundwater depletion from coastal aquifers also exposes these resources to saltwater intrusion or upconing of brackish or saline water when the volume of the freshwater body shrinks. The aquifer gets increasingly saline, eventually to the point where either wells have to be abandoned or some way of treating the pumped water has to be set up. Corrosion of the pumping infrastructure also aggravates with increased salinity.

Groundwater depletion may also have other implications to water quality than the increase of salinity. The expanding cone of depression may induce an influx of pollutants to the pumping well. When the abstraction gradually advances to deeper parts of the aquifer with progressing depletion, pumped groundwater commonly contains higher concentrations of dissolved solids.

In several zones around the world, intensive abstraction of groundwater from thick sedimentary unconsolidated aquifer-aquitard systems has been accompanied by land subsidence, which has damaged or may potentially damage infrastructure, including networks and buildings [31,32].

The Quaternary aquifers of The Netherlands offer a typical example of groundwater systems where the water-budget constraint is irrelevant for groundwater quantity management, since the latter is completely governed by environmental functions of the groundwater systems. Extremely flat topography and very shallow groundwater levels enable that during dry spells in most of the territory agricultural crops get supplemental water supplied by upward seepage, which contributes very significantly to crop yield. Furthermore, most of the country's wetlands are groundwater-fed and part of the territory is subject to land subsidence risks. The water boards, established many centuries ago to prevent inundations and water-logging, are controlling the water levels within strict limits, in order to comply with the demands imposed by the environmental functions described above. Groundwater abstractions - except very small ones — are subject to a permit system and permits are granted only if a reliable and independent study has predicted that the proposed abstraction will not significantly affect the groundwater level regime [33].

In other cases, groundwater-related environmental concerns may be present as well, but not so prominent as to overrule the groundwater-budget constraint completely. The trade-offs between the benefits of increased groundwater development and its environmental repercussions (such as the disappearance of springs) will provide a rational basis for decision-making on groundwater quantity management.

\subsection{Developing Non-renewable Groundwater Resources: Beyond Sustainability?}

In cases where present day aquifer replenishment is very limited but aquifer storage is very large, the groundwater resource is termed non-renewable (although groundwater resources are never strictly non-renewable). A lack of significant replenishment is commonly a consequence of very low rainfall 
in the unconfined zones of the aquifer, but can also result from hydraulic inaccessibility in some confined aquifer. As discussed in Foster and Loucks [34], using the term "non-renewable groundwater resource" makes practical sense when the time needed for replenishment of the resource is very long in relation to the time frame of human activity in general and of water resources planning in particular. Groundwater abstraction from such an aquifer involves "mining" groundwater in storage.

As emphasized in Foster and Loucks [34], the inter-generational distribution of benefits which focuses on the improvement of social equity over time, should be a core requirement for successful planning of the mining of non-renewable groundwater resources. They mention the following as indicators of improvement of social equity: improvements in the well-being of people, enhancement of "social capital", or the capacity of stakeholders to cooperate on resource utilization and opportunities for younger generations, created for example by technological breakthroughs that make alternative water supplies better available.

Louvet and Margat [35] summarize the key principles that should be adopted for the development of non-renewable groundwater resources as follows:

(1) The evaluation phase should result in estimates of the volume of groundwater that can be produced in a fixed time-horizon with reference to an acceptable groundwater level decline.

(2) The development of non-renewable resources must be justified by socio-economic circumstances in the absence of other water resources, and its implementation should be planned and controlled.

The feasibility of different long-term aquifer development scenarios can be inferred from demand projections related to specific socio-economic development plans. Based on the chosen development scenario, using a computer model of the aquifer system, well fields can be designed that optimize yield, defining the number of production wells needed and the likely pumping lifts. Practical constraints may include, for example, a maximum permissible drawdown, acceptable operating costs and avoiding parts of the aquifer with inferior groundwater quality [36]. The costs of exploitation depend on the chosen design and are likely to increase over time when declining groundwater levels lead to greater pumping lifts and possibly to changes in groundwater quality that require more intensive water treatment. Regrettably, in many countries (especially arid ones) groundwater is being mined in an uncontrolled and unplanned manner.

A plan for depletion, or mining, of a non-renewable groundwater resource must include an 'exit' strategy, that is, an indication of what to do after the resource becomes seriously depleted. This may involve resorting to alternative water sources (conventional or non-conventional), reducing water demands and/or relocating uses and users, where feasible. A successful exit strategy would normally imply that by the time the groundwater resource is substantially depleted, society will have used it to advance economically, socially and technically so as to enable future generations to develop substitute water sources at an affordable cost. Such a strategy may also mean strengthening the capacity of water-users to cooperate in managing water resources more efficiently [37].

'Sustainability' in the context of 'mining aquifer storage' has been interpreted by Al-Eryani et al. [37] in the 'social context', not meaning to imply 'preserving' the groundwater resource for generations to come, but instead reconciling the use of the non-renewable resource with 'sustainability of human life'. 
As relevant data on the status of the aquifer are commonly limited, as many abstractors are involved and as impacts are not easily detected and commonly emerge with a delay, there are substantial uncertainties and risks that have to be taken into account in managing non-renewable groundwater resources. Due to the above-mentioned reasons, and as damage to the groundwater resource from depletion has irreversible long-term consequences, management of the resource should ideally be adaptive, subject to periodic review and adjustment of plans, in response to changing circumstances and in light of improved knowledge.

In the 'planned depletion scenario' the socially-sustainable criterion requires orderly utilization of aquifer reserves (of a system with little pre-existing development), minimizing quality deterioration and maximizing groundwater productivity, with expected benefits and predicted impacts over a specified time frame. The overall goal should be to use groundwater in a manner that maximizes long term economic and social development of the community and decreases, over time, the frequency and severity of threats to society, leaving people better prepared to cope with socio-economic stresses associated with increasing water scarcity as aquifer storage is depleted. This will often entail the initiation and expansion of high added-value economic activities that are not water intensive [37]. So, planned and socially-sustainable mining of groundwater resources helps maximize benefits for the community, but regulations to control groundwater abstraction have to be vigorously enforced.

Many large aquifers in the sedimentary basins of northern Africa that contain essentially non-renewable groundwater resources are transboundary, meaning that international cooperation among the countries sharing the aquifer is necessary in managing them, including monitoring the status of the resource and exchanging this information.

\subsection{Economic and Financial Aspects of Storage Depletion}

It goes without saying that abstracted groundwater has an economic value. But keeping groundwater in situ has an economic value as well. When the groundwater resource gets depleted, groundwater development costs increase and the aquifers' capacity to provide the variety of environmental services, as described previously, decreases with sinking groundwater level and diminished natural discharge. The cost of abstracting the resource increases with the need to lift groundwater from increasingly greater depths, and hence the cost-benefit ratio of groundwater use changes over time. The procedure of discounting, adjusts for future values of related services by accounting for time differences. There is a degree of uncertainty involved in assuming an appropriate discount rate and the discounting procedure is in practice less suitable to address values on the very long term. Higher discount rates - by giving less weight to future net benefits - encourage present use of the resource [38].

Failure to recognize the economic value of water - as recognized in the Dublin Statement on Water and Sustainable Development [39] — has led to wasteful and environmentally damaging uses of the resource. In practice, factors contributing to groundwater depletion may include a lacking price signal reflecting the scarcity value of the groundwater threatened by depletion, the failure to take all costs and benefits into account when making decisions about groundwater abstraction and possibly also the politics of prioritizing certain sectors, to mention a few. In general, basic economics require that the price of a service be at least as high as the cost of providing that service. In the context of water supply, 
sustainable cost recovery, which utilities are encouraged to aim for, includes operating and financing costs as well as the cost of renewing existing infrastructure [40]. Rogers et al. [41] argue that sustainable and efficient use of water require the tariff to match not only costs of supply (i.e., operation and management, capital costs), but also opportunity costs, economic externality costs, and environmental externality costs. From the perspective of economic theory, there is a so-called contemporaneous opportunity cost for not having the water available for another current use. If current use depletes the groundwater stock to the extent that it makes groundwater unavailable for future, then there is the intertemporal opportunity cost of not having the water available for future use. Water uses may have an additional cost if the use of water renders it unfit for other uses by having an adverse effect on water quality, hence having negative impacts on other water uses [42].

Groundwater storage depletion and the associated groundwater level declines have two-fold economic impacts for those interested in groundwater abstraction: higher groundwater development cost and a reduced value of the remaining groundwater volume stored. They may have a negative impact as well on groundwater-related environmental functions and conditions. All these impacts constitute an economic loss, only acceptable if balanced or exceeded by the benefits produced by the abstracted groundwater. How economic and financial aspects are or may be taken into account in decisions on groundwater development depends on the perspective: an individual groundwater pumper will have different interests and thus will make different decisions related to the aquifer's exploitation than the local community. This will be illustrated below.

A farmer who owns and uses a well for the supply of irrigation water will be unpleasantly surprised if he is confronted by steadily declining groundwater levels, year after year. From the onset, the water level declines will reduce well yield and increase the unit cost of pumping, thus gradually eroding profits of irrigated agriculture. Investments may be needed after some time to deepen the well and/or to replace the pump by a more powerful one. Whether these investments are made by the farmer or not depends on his judgment on economic feasibility of continued groundwater pumping and on his access to the required financing. Many individual farmers will sooner or later decide to give up, because the economic profitability of pumping is disappearing or they cannot afford to continue pumping. This effect provides feed-back from the users to the aquifer system, contributing to conservation of groundwater.

The individual farmer will be concerned about increasing pumping costs of his own well. But he usually does not care about how he contributes to a reduction in the volume and economic value of stored groundwater, nor to increased pumping cost of other groundwater users, nor to diminished access of future generations to groundwater, nor to groundwater-related environmental degradation. To him, these aspects are 'externalities', representing costs to be shared by all who make use of the same 'common pool' - in this case the aquifer and its related ecosystems. The existence of these externalities explains why decisions made at the individual level may diverge from socially optimal decisions, which is a justification for government interventions.

The Upper Guadiana Basin, where groundwater acts as the main driver behind the region's prosperity by supporting irrigated agriculture for the past decades, illustrates the related management challenges. The development of irrigation based on groundwater from the Mancha Occidental aquifer has come at a significant environmental cost, giving rise to long-standing conflicts, and there are concerns as to its mid-term sustainability. Uncontrolled intensive pumping by individual farmers has 
dramatically lowered water tables and has caused considerable negative environmental impacts on groundwater-dependent wetlands, streams and rivers. A large proportion of the wells are currently illegal, which makes it difficult to manage water resources [43,44].

At the level of the community, the mentioned externalities should be incorporated into the groundwater quantity management approach. Plans for groundwater management should not only consider the benefits of pumped groundwater and the increase of pumping cost due to storage depletion, but also the associated change in value of groundwater stored and the allocation of all cost and benefits-including intergenerational allocation. This involves a rather complex balancing of components, which may be guided by optimization approaches analogous to those presented by Neher [45] for natural resources management in general.

Neher's approach basically consists of a set of three equations: the first one is maximizing over time the profit from using the resource ("Maximum Principle"), the second one is maximizing over time the value of stock and abstracted volumes combined (Portfolio balance equation) and the third one takes into account the mass balance of the resource considered. Uncertainties in economic parameters preclude their use for the development of reliable decision rules for the long term, but applying the methodology deepens insight in trade-offs between now and later, and between using flow (capture) versus using stock (stored groundwater).

In cases that allow simplification, simple decision rules may be helpful. An example is 'Burt's approximate decision rule' for intertemporal allocation of groundwater abstraction from isolated groundwater reservoirs [46]. Another example is the so-called 'Hotelling rule', applied in the oil industry to optimize exploitation patterns over time [46,47]. The basic principle used-exploiting the resource during periods when the stock value's growth rate is smaller than the capital growth rate (discount rate) - may guide as well to some extent the planning of the exploitation of non-renewable groundwater resources.

Environmental costs are rather difficult to assess and incorporate in groundwater resources management. They consist of the environmental damage costs of aquatic ecosystem degradation and depletion caused by a particular water use such as water abstraction. Following the definition in the Wateco guidance [48], a distinction can be made between damage costs to the water environment and to those who use the water environment. Interpreted in terms of the concept of total economic value, one could argue that the environmental damage costs refer to non-use values attached to a healthy functioning aquatic ecosystem, while the costs to those who use the water environment refer to the corresponding use values. Use values are associated with the actual or potential future use of a natural resource (e.g., drinking water, irrigation water). Non-use values are not related to any actual or potential future use, but refer to values attached to the environment and natural resource conservation based on considerations that, for example, the environment should be preserved for future generations [49].

In conclusion, groundwater storage depletion may have significant financial and economic implications. Therefore, these aspects are relevant for both individual decisions to be made and groundwater resources management in relation to the rate of groundwater storage depletion. 


\section{Groundwater Resources Development and Sustainability}

\subsection{Groundwater Storage: Blessing and Concern}

Groundwater systems tend to have large volumes of water in storage, usually equivalent to the recharge of several tens to several thousands of years. These large storage volumes are a blessing, for a number of reasons. They keep water available during prolonged dry periods, when no rain is occurring and stream flows have become minimal or even zero. As a result, people have been able to settle in areas where otherwise human life would be impossible or extremely difficult due to annually recurring dry seasons (most arid and semi-arid zones), or even due to absence of significant rain during the last centuries or millennia (e.g., a large part of Northern Africa, where most recent significant groundwater recharge occurred thousands of years ago). Available groundwater storage does contribute not only to reliable public and industrial water supplies, but also to dependable irrigation water supplies. The latter is not only important to secure food supplies, it has also very positive economic impacts. The fact that groundwater sources tend to be more reliable and predictable than surface water sources often results in significantly higher economic returns per cubic meter of water used for irrigation $[23,50]$.

The same groundwater storage provides a reason for concern as well. If surface water users abstract water from streams at a hydrologically unsustainable rate, then most streams will rather quickly give feed-back by reducing their flow rates, which forces abstractions to be reduced or even to be stopped. In the case of intensive groundwater abstraction the feed-back is much weaker. Groundwater levels will drop indeed, but the large groundwater volume in storage allows well owners to continue excessive pumping usually for many years. Consequently, pro-active rather than reactive groundwater quantity management is needed to protect the sustainability of the aquifer's abstraction potential and its groundwater-related environmental functions. As a sound basis for making the related decisions, groundwater monitoring with sufficient spatial and temporal resolution is required for detecting and observing storage depletion reliably. Lack of control may lead to practically irreversible losses of aquifer functionalities, in other words it may undermine sustainability. Yemen is illustrative for countries being exposed to such a risk [51].

\subsection{Groundwater Quantity Management Is Based on Preferences}

As mentioned before, groundwater pumping causes depletion of groundwater storage and changes the groundwater regime, thus modifying groundwater levels, groundwater in- and outflows and groundwater quality. These modifications have their impacts on people, ecosystems and the environment. In the majority of cases, such impacts are negative, as opposed to the anticipated positive impacts of the abstracted groundwater. One should be aware that impacts do not only depend on the rate of abstraction, but also on their spatial arrangement and on the pumping schedules. Simulation models may help exploring the role of these factors. Furthermore, to what extent an impact is considered negative or positive is a judgment that is both subjective and dependent on time and location. For example, disappearance of water-logging conditions due to pumping may have been considered fifty years ago by most people as 'waste land recovery', whereas the same feature in several parts of the world nowadays tends to be considered rather as a loss of a valuable wetland. 
It is an illusion to think that proper groundwater management will allow groundwater abstraction to take place without affecting any of the aquifer's functions and services negatively. One has to sacrifice almost always something in exchange. Therefore, the designation 'sustainable' should not be interpreted too rigorously. As long as groundwater pumping does not threaten to exhaust the aquifer and society considers the benefits from pumping to outweigh the associated negative impacts_-both integrated over a prolonged period of time, one may speak of sustainable groundwater development. It is the challenge of groundwater resources management to strike a balance between the gains due to pumping and the losses pumping may cause as a result of depletion. This balance is based on preferences, not on 'absolute' values derived from knowledge. In more technical terms, one may characterize this as a multi-objective decision process - moving along the Pareto frontier - rather than an optimization process subject to constraints. It is important to consider who benefits and who loses when the balance and distribution of costs and benefits upon the abstraction of the resource evolves. Hence, equity is a common objective in the decision process, together with other key objectives such as meeting basic needs for water, sustainability of the water sources and economic efficiency. The decision process requires sufficient reliable local data to be available, and will benefit from a proper diagnostic analysis and intelligent use of decision support systems.

After adopting preferences as a core element of decision-making in groundwater management, it remains to be decided whose preferences should be considered, how to define these preferences and how to incorporate them in the planning process. In most parts of the world, the idea is winning ground that not only technical specialists and politicians should be involved, but local stakeholders as well. After all, their interests are at stake, their perceptions of the local conditions and problems may give valuable guidance and their support is crucial for the successful implementation of groundwater management measures. Therefore, stakeholder participation is becoming in many parts of the world an important component of groundwater resources management.

\subsection{Dominating Concerns and Constraints Vary Geographically}

Although groundwater resources management is based on preferences, geographical variations in physical and socio-economic setting leave their mark as well. Evidently, in water-scarce arid and semi-arid zones where no significant surface water resources are available, people easily sacrifice groundwater-related environmental functions if that will allow them to pump more groundwater. In such cases they opt usually for a level of groundwater pumping that is only constrained by the water budget (see Section 2). In more humid zones, the relative abundance of water and the presence of surface water as an alternative source of water tend to favor shifting priorities to conserving springs, baseflows, wetlands and other groundwater-supported features (see Section 3). This leads to adopting constraints to groundwater pumping that are much more restrictive than the water budget constraint, especially in wealthy countries that can afford a relatively high cost of water supplies. Furthermore, groundwater pumping regimes in coastal areas are first and for all constrained by the priority of preventing intrusion of sea water or upconing of saline water underlying fresh groundwater. These and other differences in setting are reflected in distinct geographical patterns of dominating constraints to groundwater pumping. 


\subsection{What Matters Is Overall Sustainability}

Groundwater systems are important, but their importance from a human perspective lies mainly in the functions and services they provide. Partially, these functions and services are not unique for groundwater systems and may be provided by other water system components as well. This is in particular the case for the water supply function: in most regions one may choose between groundwater and surface water, or even desalinized seawater and non-conventional sources such as treated waste-water, as alternative sources for satisfying the same water demand. Therefore, 'overall sustainability' is important, i.e., the sustainability of valuable functions and services, rather than the sustainability of the groundwater systems per se. The consequence is that groundwater development and management should be viewed in an integrated water resources management perspective, or even in a broader regional development context. The key question then is not whether the development of a particular groundwater system is sustainable, but rather whether the complex of natural resources (to which that groundwater system belongs) allows and supports sustainable socio-economic development and preservation of desired environmental conditions in the region. Even properly planned development of non-renewable groundwater resources - certainly a non-sustainable activity in the physical sense — could in principle contribute to this overall sustainability.

\section{Conclusions}

Sustainability is a very complex concept. Its practical interpretation depends on the systems considered, the angle of view, the overall local context and subjective comparisons between alternative futures. Applied to groundwater abstraction, it makes a difference whether one has sustainable pumping in mind or the sustainability of the local society and ecosystems. In the latter perspective, even unsustainable pumping from a non-renewable groundwater resource might contribute to sustainable development, provided that other water resources are available to meet water demands on the long run, after the non-renewable groundwater resource will be exhausted. Furthermore, the extent of storage depletion due to pumping may vary from case to case, and the same is true for the impacts of storage depletion. Such impacts tend to be more severe in arid than in humid climates, because buffering by other components of the water cycle there is less likely to occur. In addition, whether one is able to cope with certain physical impacts varies according to the local conditions. Wealthy developed societies - with good access to financial resources and technology — are in this respect in a more favorable position than poor developing countries.

Whatever perspective is chosen, it is clear that groundwater development always comes at a cost (environmental, financial or otherwise). It is up to society to decide whether this cost is balanced or outweighed by the benefits of the abstracted groundwater and does not threaten sustainable development. In order to underpin such a decision adequately, it is important to have a good picture of the groundwater system considered, to understand its response to pumping (avoiding the 'water budget myth' and other erroneous concepts) and to oversee its socio-economic and environmental setting. 


\section{Acknowledgements}

The authors kindly acknowledge the useful comments and constructive criticism received from two anonymous reviewers, contributing to the improvement of this paper. The views expressed in this article are those of the authors and do not necessarily reflect the views of the United Nations Economic Commission for Europe.

\section{References and Notes}

1. Theis, C.V. The source of water derived from wells: essential factors controlling the response of an aquifer to development. Civil Eng. 1940, 10, 277-280.

2. In this paper we use the word 'depletion' to indicate a reduction in the volume of groundwater stored, whereas 'exhaustion' is used to indicate that no or no usable groundwater is left.

3. Hiscock, K.M.; Rivett, M.O.; Davison, R.M. Sustainable groundwater development. In Sustainable Groundwater Development; Hiscock, K.M., Rivett, M.O., Davison, R.M., Eds.; Special Publications 193; Geological Society: London, UK, 2002; pp. 1-14.

4. United Nations World Commission on Environment and Development. Our Common Future; Oxford University Press: Oxford, UK, 1987.

5. Devlin, J.F.; Sophocleous, M. The persistence of the water budget myth and its relationship to sustainability. Hydrogeol. J. 2005, 13, 549-554.

6. Alley, W.M.; Leake, S.A. The journey from safe yield to sustainability. Ground Water 2004, 42, 12-16.

7. Kalf, F.R.P.; Woolley, D.R. Applicability and methodology of determining sustainable yield in groundwater systems. Hydrogeol. J. 2005, 13, 295-312.

8. Lee, C.H. The determination of safe yield of underground reservoirs of the closed basin type. Trans. Amer. Soc. Civil Eng. 1915, 78, 148-151.

9. Todd, D.K. Ground Water Hydrology; Wiley: New York, NY, USA, 1959.

10. Sophocleous, M. Managing water resources systems: Why "safe yield" is not sustainable. Groundwater 1997, 35, 561.

11. Bredehoeft, J.D.; Papadopoulos, S.S.; Cooper, H.H., Jr. The water budget myth. In Scientific Basis of Water Resources Management Studies in Geophysics; National Academy Press: Washington, DC, USA, 1982; pp. 51-57.

12. Bredehoeft, J.D. Safe yield and the water budget myth. Ground Water 1997, 35, 929.

13. Bredehoeft, J.D. The water budget myth revisited: Why hydrogeologists model. Ground Water 2002, 40, 340-345.

14. Alley, W.M.; Reilly, T.E.; Franke, O.L. Sustainability of Ground-water Resources; U.S. Geological Survey Circular 1186; USGS Information Services: Denver, CO, USA, 1999.

15. Sophocleous, M. From safe yield to sustainable development of water resources: The Kansas experience. J. Hydrol. 2000, 235, 27-43.

16. Sophocleous, M. Groundwater recharge and sustainability in the high plains aquifer in Kansa, USA. Hydrogeol. J. 2005, 13, 351-365.

17. Sophocleous, M. Science and practice of environmental flows and the role of hydrogeologists. Ground Water 2007, 45, 393-401. 
18. Sophocleus, M.; Devlin, J.F. Discussion on the paper "The water budget myth revisited: why hydrogeologists model” by John Bredehoeft. Ground Water 2004, 42, 618.

19. Zhou, Y. A critical review of groundwater budget myth, safe yield and sustainability. J. Hydrol. 2009, 370, 207-213.

20. Lohman, S.W.; Bennett, R.R.; Brown, R.H.; Cooper, H.H., Jr.; Drescher, W.J.; Ferris, I.G.; Johnson, A.I.; McGuinness, C.L.; Piper, A.M.; Rorobaugh, M.I.; Stallman, R.W.; Theis, C.V. Definitions of Selected Ground/Water Terms-Revisions and Conceptual Refinements; Geological Survey Water-Supply Paper 1988; U.S. Government Printing Office: Washington, DC, USA, 1972.

21. Government of India. Ground Water Estimation Methodology; Report of the Groundwater Estimation Committee, Ministry of Irrigation: New Delhi, India, 1984.

22. Chatterjee, R.; Purohit, R.R. Estimation of replenishable groundwater resources of India and their status of utilization. Curr. Sci. 2009, 96, 1581-1591.

23. Shah, T. The Groundwater Economy of South Asia: An Assessment of Size, Significance and Socio-ecological Impacts. In The Agricultural Groundwater Revolution: Opportunities and Threats to Development; Giordano, M., Villholth, K.G., Eds.; CABI: Wallingford, UK, 2007; pp. 7-36.

24. Water Resources of the Sultanate of Oman; An Introductory Guide; Ministry of Water Resources of Oman (MWR): Muscat/Ruwi, Oman, 1991.

25. Petry, B.; van der Gun, J.; Boeriu, P. Coping with water scarcity: A case history from Oman. In Proceedings of the Conference on Cooping with Water Scarcity, Hurgada, Egypt, 26-28 August, 1998; pp. 3.12.1-3.12.15.

26. Winter, T.C.; Harvey, J.W.; Franke, O.L.; Alley, W.M. Ground Water and Surface Water: A Single Resource; U.S. Geological Survey Circular 1139; US Geological Survey: Denver, CO, USA, 1998.

27. Alvarado, J.; Camacho, A.; Diaz, J.; Gonzales, C.; van der Gun, J.A.M.; Huaranca, R.; de Louw, P.; Revollo, A.; Rios, R.; Villegas, E. Estudio para el Control y la Protección de las Aguas Subterráneas en el Valle Alto; Informe técnico del proyecto CPAS: Cochabamba, Bolivia, 1998.

28. Konikow, L.F; Kendy, E. Groundwater depletion: A global problem. Hydrogeol. J. 2005, 13, 317-320.

29. Bergkamp, G.; Cross, K. Groundwater and Ecosystem Services: Towards Their Sustainable Use. In Proceedings of the International Symposium on Groundwater Sustainability (ISGWAS), Alicante, Spain, 24-27 January 2006; pp. 177-193.

30. Submarine Groundwater Discharge: Management Implications, Measurements and Effects; Scientific Committee on Oceanic Research (SCOR)/Land-Ocean Interactions in the Coastal Zone (LOICZ), UNESCO: Paris, France, 2004; IHP-VI Series on Groundwater No.5.

31. Poland, J.F.; Carbognin, L.; Vega, F.G.; Johnson, A.I.; Yamamoto, S. Guidebook to Studies of Land Subsidence due to Ground-water Withdrawal; Studies and Reports in Hydrology, UNESCO: Paris, France, 1984; p. 305. 
32. Land Subsidence: Proceedings of the Fifth International Symposium on Land Subsidence, The Hague, The Netherlands, 16-20 October 1995; Barends, F.B.J., Brouwer, F.J.J., Schröder, F.H., Eds.; IAHS Publication No. 234.

33. Dufour, F.C. Groundwater in The Netherlands-Facts and Figures; Netherlands Institute of Applied Geoscience TNO: Delft/Utrecht, The Netherlands, 2000; p. 96.

34. Groundwater Resources: A Guidebook on Socially-Sustainable Management for Water-Policy Maker; Foster, S., Loucks, D.P., Eds.; UNESCO: Paris, France, 2006; IHP-VI, Series on Groundwater No. 10.

35. Louvet, J.M.; Margat, J. Quelles ressources en eau les grands réservoirs aquifères offrent ils? Évaluation et stratégie d'exploitation. In Proceedings of the International Conference 'Regional Aquifer Systems in Arid Zones-Managing Non-Renewable Resources', Tripoli, Libya, 20-24 November 1999; UNESCO: Paris, France, 2006; IHP-V Technical Documents in Hydrology 42.

36. Puri, S.; Margat, J.; Yurtsever, Y.; Wallin, B. Aquifer characterization techniques. In Groundwater Resources: A Guidebook on Socially-Sustainable Management for Water-Policy Makers; Foster, S.; Loucks, D.P., Eds.; UNESCO: Paris, France, 2006; IHP-VI, Series on Groundwater No. 10, pp. 35-48.

37. Al-Eryani, M.; Appelgren, B.; Foster, S. Social and economic dimensions of non-renewable resources. In Groundwater Resources: A Guidebook on Socially-Sustainable Management for Water-Policy Makers; Foster, S., Loucks, D.P., Eds.; UNESCO: Paris, France, 2006; IHP-VI, Series on Groundwater No. 10, pp. 25-34.

38. NRC (National Research Council). Valuing Ground Water: Economic Concepts and Approaches; National Academy Press: Washington, DC, USA, 1997.

39. Dublin Statement on Water and Sustainable Development. In Proceedings of the International Conference on Water and Environment, Dublin, Ireland, 26-31 January 1992.

40. Winpenny, J. Financing Water for All: Report of the World Panel on Financing Water Infrastructure; World Water Council and Global Water Partnership: Marseille, France, 2003; Available online: http://www.worldwatercouncil.org/fileadmin/wwc/Library/Publications_and_ reports/CamdessusSummary.pdf (accessed on 3 May 2010).

41. Rogers, P.; de Silva, R.; Bhatia, R. Water is an economic good: How to use prices to promote equity, efficiency, and sustainability. Water Policy 2002, 4, 1-17.

42. Kahn, J. The Economic Approach to Environmental and Natural Resources; The Dryden Press: Fort Worth, TX, USA, 1998.

43. Llamas, M.R.; Varela-Ortega, C.; de la Hera, A.; Aldaya, M.M.; Villarroya, F.; Martínez-Santos, P.; Blanco-Gutiérrez, I.M.M.; Carmona-García, G.; Esteve-Bengoechea, P.; De Stefano, L.; Hernández-Mora, N.; Zorrilla, P. The Guadiana Basin. In The Adaptive Water Resource Handbook; Mysiak, J., Henrikson, H.J., Sullivan, C., Bromley, J., Pahl-Wostl, C., Eds.; Earthscan: London, UK, 2010; Chapter 6, pp. 103-115.

44. Martínez-Santos, P.; Llamas, M.R.; Martínez-Alfaro, P.E. Vulnerability assessment of groundwater resources: A modelling based approach to the Mancha Occidental aquifer, Spain. Environ. Modell. Softw. 2008, 23, 1145-1162.

45. Neher, P.A. Natural Resources Economic; Cambridge University Press: Cambridge, UK, 1990; pp. ix, 360 . 
46. Domenico, P.A. Concepts and Models in Groundwater Hydrology; McGraw-Hill: New York, NY, USA, 1972.

47. Hotelling, H. The Economics of Exhaustible Resources. J. Polit. Econ. 1931, 39, 137-175.

48. Working Group 2.6-WATECO. Economics and the Environment: The Implementation Challenge of the Water Framework Directive; Coomon Implementation Strategy for the Water Framework Directive (2000/60/EC), Guifdance Document No. 1.; European Communities: Luxembourg, 2003.

49. ECO2 (Drafting Group). Assessment of Environmental and Resource Costs in the Water Framework Directive; Information Sheet; Common Implementation Strategy, Working Group 2B: Lelystad, The Netherlands, 2004.

50. Llamas, M.R.; Garrido, A. Lessons from Intensive Groundwater Use in Spain: Economic and Social Benefits and Conflicts. In The Agricultural Groundwater Revolution: Opportunities and Threats to Development; Giordano, M., Villholth, K.G., Eds.; CABI: Wallingford, UK, 2007; pp. 266-298.

51. van der Gun, J.A.M. Water Resources Scarcity in Yemen: A Time Bomb under Socio-economic Development? In Water: A Looming Crisis? Proceedings of the International Conference on World Water at the Beginning of the 21st Century, Paris, France, 3-6 June 1998; IHP-V, Technical Documents in Hydrology, No. 18, pp. 379-384.

(C) 2010 by the authors; licensee MDPI, Basel, Switzerland. This article is an open access article distributed under the terms and conditions of the Creative Commons Attribution license (http://creativecommons.org/licenses/by/3.0/). 